\title{
PÉRDIDAS, MUERTE Y DUELO ANTE PANDEMIAS: “PONER AMOR DONDE HAY DOLOR". EL VELO PINTADO, EL AMOR EN TIEMPOS DE CÓLERA Y LA CIUDAD DE LA ALEGRÍA
}

\author{
Loss, Death and Grief in the Face of Pandemics: "Putting Love where there \\ is Pain". The Painted Veil, Love in the Time of Cholera and The City of Joy
}

\author{
M. ${ }^{a}$ Patricia ACINAS ACINAS \\ Sociedad Española de Psicología Aplicada a Desastres, Urgencias y Emergencias (SEPADEM) (España). \\ Correo electrónico: acinas.patricia@gmail.com
}

Fecha de recepción: 16 de septiembre de 2020

Fecha de aceptación: 25 de septiembre de 2020

Fecha de publicación: 29 de enero de 2021

\section{Resumen}

El dolor del duelo tras una pérdida real o percibida es un dolor que invade nuestra vida y transforma nuestra biografía. Una situación de epidemia o pandemia provoca que la muerte se produzca en condiciones más duras y complejas; en ocasiones impide la despedida afectiva de la persona fallecida por mantener las normas que evitan el contagio de la enfermedad. Y el dolor se acrecienta. Entre las diversas maneras de afrontar el dolor de la pérdida, está prestar atención al amor que nos ha dejado la persona fallecida o las personas que nos rodean tras el deceso. Vamos a extraer varias enseñanzas de tres películas que nos hablan de la muerte desde lo más profundo del corazón.

Palabras clave: muerte; duelo; pérdida; amor; resiliencia.

\section{Abstract}

The pain of grief after a real or perceived loss is a pain that invades our lives and transforms our biography. An epidemic or pandemic situation causes death under harsher and more complex conditions; sometimes it prevents the emotional farewell of the deceased person by 
maintaining the rules that prevent the spread of the disease. And the pain grows. Among the various ways of coping with the pain of loss, is paying attention to the love that the deceased person or the people around us have left us after the death. We are going to extract several lessons from three films that tell us about death from the bottom of the heart.

Keywords: Death; grief; loss; love; resilience.

"El más difícil no es el primer beso sino el último". (Gabriel García Márquez)

\section{PERDIDAS Y DUELOS}

Cuando se produce una enfermedad, del tipo que sea, aparecen numerosas pérdidas de la salud, de la autonomía, del bienestar, de la independencia, de la capacidad de tomar decisiones (las toman los profesionales sanitarios), de la intimidad, de la privacidad ${ }^{1}$.

El duelo es una experiencia personal, subjetiva, individual, que requiere recorrer un camino para su elaboración. Algunos autores hablan de cuatro tareas para recorrer el camino de la pérdida²; otros hablan desde una perspectiva más constructivista $^{3}$ de que es necesario reconstruir el complejo de significados de la persona desde su experiencia biográfica.

Por otro lado, debemos tener en cuenta que somos seres en relación y que la elaboración también debe llevarse a cabo dentro de un medio social. En ocasiones hay elementos traumáticos asociados a la experiencia de duelo que también hay que saber trabajar ${ }^{4}$. Ante una situación de pandemia o emergencia continuada, cuando no es posible la despedida, surgen inevitablemente elementos traumáticos y puede llegar a coexistir aspectos de duelo y de trauma psicológico. De hecho, en muchos casos los aspectos traumáticos son los primeros que aparecen, y hasta que no se elaboran no se puede abordar el duelo como tal.

Pero también de una experiencia altamente dolorosa, también se puede aprender, sacar enseñanzas para la vida, para nosotros mismos y para otros ${ }^{5}$; podemos llegar a salir fortalecidos por lo vivido, con resiliencia e incluso un crecimiento postraumático.

A veces el camino hacia la propia muerte está lleno de aspectos que nos hacen ver la vida con amor y con cariño $0^{6}$, y se puede tener un mal proceso de enfermedad y tener momentos finales de despedida en que haya imágenes agradables oníricas o reales, como sucede en la película Wit, amar la vida. (Mike Nichols, 2001)

\section{EL VELO PINTADO: LA MUERTE ESTÁ EN EL AMBIENTE}

A veces el viaje más largo es la distancia entre dos personas

(El velo pintado)

Título: El velo pintado.

Título original: The painted veil.

Otros títulos: Al otro lado del mundo (Argentina).

País: China, USA, Canadá.

Año: 2006.

Director: John Curran.

Música: Alexandre Desplat.

Fotografía: Stuart Dryburgh.

Montaje: Alexandre de Franceschi.

Guion: Ron Nyswaner sobre la novela homónima de W. Somerset Maugham.

Intérpretes: Naomi Watts (Kitty Fane), Edward Norton (Dr Walter Fane), Liev Schreiber (Charlie Townsend), Catherine An (Hostess Anfitriona), Bin Li, Bin Wu, Alan David (Dr Garstin), Marie-Laure Descoreaux (Hermana San Joseph), Sally Hawkins (Mary), Juliet Howland (Dorothy Townsend), Toby Jones (Waddington), Lorraine Laurence, Johnny Lee, Li Feng, Gesang Meiduo, Ian Renwick, Diana Rigg (Madre Superiora), Cheng Shihan (Warlord Kwei), Maggie Steed (Sra Garstin), Lucy 
Voller, Anthony Wong (Coronel Yu), ChauSang, Zoe Telford (Leona), Xia Lu (Wu Lien), Lü Yang (Wan Xi).

Color: color.

Duración: 125 minutos.

Género: drama, romance.

Idioma original: inglés.

Productoras: WIP, Stratus Film Co., Bob Yari Productions, Class 5 Films, The Colleton

Company, Dragon Studios, Emotion Pictures, The Mark Gordon Company, Warner China Film HG Corporation.

Sinopsis: Años veinte. Kitty (Naomi Watts) es una joven inglesa de la alta sociedad que, para escapar de su ambiente familiar, se casa con Walter (Edward Norton), un prometedor médico. El matrimonio se traslada a Shangai, donde Kitty tiene una aventura con un norteamericano (Liev Schreiber). Cuando Walter descubre la infidelidad de su esposa, decide trasladarse con ella a una de las regiones mas remotas de China, para intentar luchar contra una mortal epidemia de cólera (Filmaffinity).

Premios: Globo de Oro a la Mejor Banda Sonora en 2007.

Enlaces:

http://www.filmaffinity.com/es/film406338. html

http://www.imdb.com/title/tt0446755

Tráiler en español

Tráiler en inglés

La película nos habla de un brote de cólera en un lugar recóndito de China al que se dirige el microbiólogo Dr Fane junto a su esposa Kitty. Los motivos por los que acude son más para alejar a su esposa de una relación infiel, que por deseo de atajar una epidemia. Cuando acudimos a un lugar donde hay enfermedades infectocontagiosas, a un lugar menos avanzado a nivel científico y técnico/tecnológico, surgen más emociones contrapuestas y ambivalentes. En este caso, Kitty se siente "castigada",

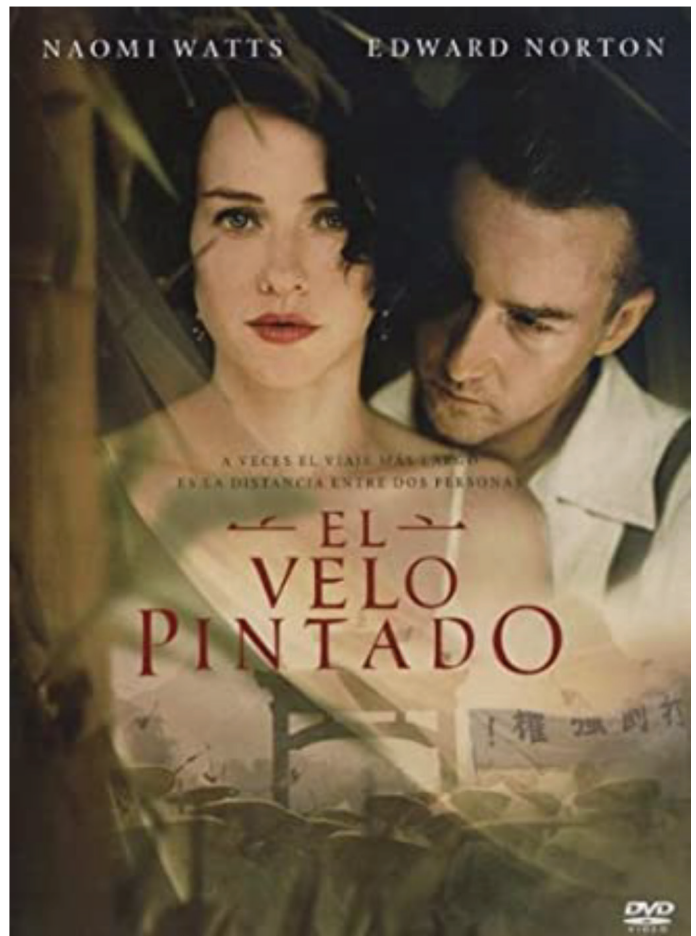

conducida sin remedio a la "boca del lobo" (por mandato de su marido), al lugar donde están presentes la enfermedad y la muerte y donde ella pierde su estatus personal (pertenece a la clase alta inglesa y debe vivir en un lugar con menos comodidades).

Una vez adaptada allí, y tras las reacciones de ira, enfado, impotencia... iniciales, y tras un periodo de aburrimiento (no tiene sus reuniones sociales), entra en contacto con el convento de Sant Joseph. Esto supone varias cosas: conocer más de cerca la enfermedad, ayudar y sentirse útil, poder ayudar a su marido, recuperar su independencia perdida tras la obligación de haber viajado a un lugar con duras condiciones. Esto nos habla de la capacidad de adaptación de los seres humanos en situaciones de dificultad, escasez de recursos y riesgo. Nos lleva a la resiliencia de las personas en situaciones críticas. 
En la película se muestra el contraste entre la vida (nacen niños a pesar de la epidemia) y la muerte (mueren muchas personas por el brote de cólera), como todo forma parte de la vida como si del Ying y el Yan se tratara.

La epidemia se propaga rápidamente por la falta de medidas higiénico sanitarias transmitidas a la población. Se están perdiendo vidas, pero la población local se niega a asumir medidas que disminuirían el número de bajas. Se produce un choque cultural (las costumbres de enterrar a los muertos en el cementerio, frente a necesidad de incinerar los cuerpos para evitar propagación de enfermedad y la filtración de la bacteria que produce la enfermedad a través de las aguas de uso comunitario). Esto origina una falta de adhesión a las medidas que frenarían los contagios, si la población las siguiera.

Las atribuciones que se hacen de las muertes no son tanto a la enfermedad ${ }^{7}$ sino a aspectos culturales que son aceptados por todos los de la comunidad. Sin embargo, se cuestionan las normas que se dan para que aumenten las muertes.

Como suele ocurrir ante las pérdidas y muertes, cuando hay creencias espirituales, los duelos producidos por la pérdida de personas queridas, se elaboran mejor (Foto 1).

En época de epidemias y pandemias, el contacto físico se puede volver peligroso porque puede suponer una posibilidad altísima de contagio. Por otro lado, los médicos y los profesionales sanitarios en general necesitamos acercarnos a la persona, reconocerla, hacer ciertas técnicas, exploraciones... contactos físicos y psicológicos que requieren una gran proximidad a la persona que puede estar enferma.

En cambio, ante una situación de duelo y de pérdidas, necesitamos abrazary ser abrazados para poder consolar, acompañar, y elaborar el duelo.

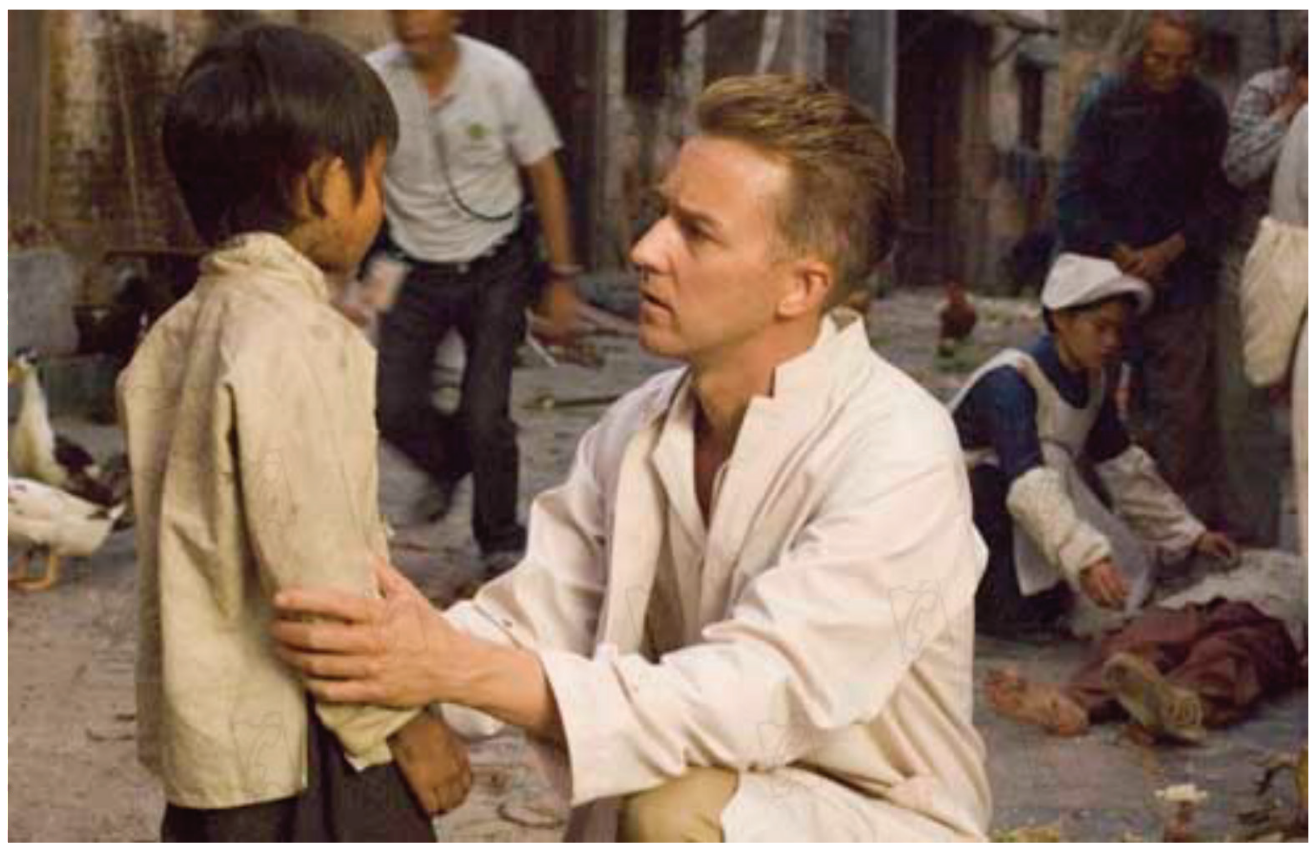

Foto 1. El Dr. Fane, se acerca a un niño que ha perdido a familiares por la epidemia de cólera para preguntarle y darle consuelo, mientras los cadáveres se amontonan en las calles. 
En la película los aspectos relacionados con la pérdida y el duelo se han desarrollado menos, pero la novela los expone con una exquisitez brillante. Vamos a plasmar algunos fragmentos de la novela para ilustrar algunos aspectos. Aunque en época de pandemia hay muertes y se colectiviza la muerte; la vivencia de la muerte de una persona conocida y querida es algo personal y casi íntimo. Por eso el libro habla de la muerte del Dr. Fane desde su propia perspectiva y de la de su esposa. Como si de un proceso se tratara (Tabla 1).

Pedir perdón al final, es algo que sucede en muchas despedidas de personas tanto de quien fallece como de quien permanece (los familiares y allegados). Es una manifestación humana, y empática, de comunicación entre seres humanos que se despiden físicamente pero que desean mantener el vínculo emocional, aunque se pierda

Tabla 1. Evolución de las manifestaciones de duelo presentes en la novela El velo pintado (W. Somerset Maugham).

\begin{tabular}{|c|c|}
\hline $\begin{array}{l}\text { ASPECTOS DESCRITOS SOBRE MUERTE } \\
\text { Y DUELO / PÁGINA DEL LIBRO }\end{array}$ & FRAGMENTO CONCRETO DEL LIBRO ${ }^{8}$ \\
\hline $\begin{array}{l}\text { Percepción de muerte en el ambiente y } \\
\text { en las personas. } \\
\text { Kitty ve que su marido va a morir al } \\
\text { llegar al lugar donde está. } \\
\text { (capitulo n. }{ }^{\circ} 63 \text {, pág. } 219 \text { ). }\end{array}$ & $\begin{array}{l}\text { Era una sala estrecha y las lámparas humeantes, la bañaban en una } \\
\text { claridad mortecina y siniestra, Había por allí, tres o cuatro celadores y } \\
\text { al otro lado de la sala, un hombre acurrucado en un jergón, a cuyos pies } \\
\text { permanecía un oficial inmóvil. } \\
\text { Kitty corrió hacia allí y se inclinó sobre el catre. Walter yacía con los ojos } \\
\text { cerrados y, bajo aquella luz sombría, su rostro penetraba la grisura de la } \\
\text { muerte, estaba terriblemente quieto. } \\
\text {-Walter, Walter, gimió ella aterrada, en un tono apenas audible. } \\
\text { Se apreció en el cuerpo del enfermo un movimiento, o la sombra de un } \\
\text { movimiento, tan leve como un soplo de aire que uno no alcanza a sentir y, } \\
\text { sin embargo, riza la superficie tranquila del agua. }\end{array}$ \\
\hline $\begin{array}{l}\text { Impotencia ante lo inevitable. Asegurar } \\
\text { haber hecho lo posible desde el punto } \\
\text { de vista humano y técnico. } \\
\text { Kitty comprende lo inminente de la } \\
\text { situación y no sabe qué puede hacer } \\
\text { (capitulo n. } .^{\circ} 63 \text {, págs. } 220 \text { y } 221 \text { ). }\end{array}$ & $\begin{array}{l}\text { Waddington habló con el oficial apostado a los pies de la cama: } \\
\text { - Me temo que han hecho todo lo posible, lo ha atendido el cirujano del } \\
\text { regimiento. Fane le enseñó cuanto sabía sobre la enfermedad. Ha hecho } \\
\text { todo lo que su marido ha hecho. (...) } \\
\text { - Es horrible no poder hacer nada. } \\
\text {-Al menos ya no sufre- señaló Waddington. } \\
\text { Ella se agachó de nuevo sobre su marido cuyos ojos vidriosos seguían } \\
\text { mirando al vacío. Kitty no sabía si aún veía u oía algo, pero acercó los } \\
\text { labios a sus oídos. } \\
\text {-Walter, ¿hay algo que podamos hacer? } \\
\text { Estaba convencida de que debía haber alguna clase de medicina que } \\
\text { administrarle para evitar... }\end{array}$ \\
\hline $\begin{array}{l}\text { Redefinir la esperanza y despedida final. } \\
\text { Kitty (capitulo } n .^{\circ} 63 \text { págs. 221-222). }\end{array}$ & $\begin{array}{l}\text { Kitty esperó a que prosiguiese, pero Walter guardo silencio. Su inmovilidad } \\
\text { le desgarraba el alma, le espeluznaba que él estuviese tan quieto, como } \\
\text { preparándose para la quietud de la tumba (...) } \\
\text { - ¿No hay la menor esperanza?- dijo en un susurro. } \\
\text { El negó con la cabeza } \\
\text { - ¿Cuánto tiempo puede seguir vivo? } \\
\text { - No hay forma de saberlo. Una hora tal vez } \\
\text { (...) } \\
\text { - ¿Puedo quedarme a solas con él, un momento?. -Preguntó-. Será } \\
\text { solo un minuto. }\end{array}$ \\
\hline
\end{tabular}

Rev. Med. Cine. 2020; 16 (e), 293-310 Ediciones Universidad de Salamanca / 
Pedir Perdón

Kitty (capítulo n. 63 págs. 221-222).
Ahora que lo impensable le había nublado la conciencia, como una droga que corriera por sus venas y ella había comprendido que Walter iba a morir, no pensaba más que una cosa, que era hacerle el final más llevadero, extirpando de su alma el rencor que la envenenaba. Se figuraba que, si al fallecer estaba en paz con ella, también estaría en paz consigo mismo. Ahora Kitty no se preocupaba de sí misma en absoluto, sino de él. -Walter, te ruego que me perdones- suplicó encorvada hacia él. Por miedo a que no soportara la presión se cuidó mucho de no tocarlo- No sabes cuánto lamento el daño que te hice. Estoy profundamente arrepentida. la conexión física. Es una especie de consuelo para la persona y a veces es un regalo final.

\section{EL AMOR EN TIEMPOS DE CÓLERA: CONFIANZA EN EL AMOR}

"El hecho de que alguien no te ame como tú quieras, no significa que no te ame con todo su ser"

(El amor en tiempos de cólera)

Título: El amor en tiempos del cólera.

Título original: Love in the Time of Cholera.

Otros títulos: Amor en tiempos de cólera.

País: EE. UU.

Año: 2007.

Director: Mike Newell.

Música: Shakira. Antonio Pinto.

Fotografía: Alfonso Beato.

Montaje: Mick Ausdley.

Guion: Ronald Harwood, basado en la novela homónima de Gabriel García Márquez.

Intérpretes: Javier Bardem (Florentino Ariza), Unax Ugalde (Florentino Ariza joven), Giovanna Mezzogiorno (Fermina Daza), Benjamin Pratt (Dr. Juvenal Urbino), John Leguizamo (Lorenzo Daza), Liev Schreiber (Lotario Thugut), Catalina Sandino Moreno (Hildebranda Sánchez), Fernanda Montenegro (Tránsito Ariza), Angie Cepeda (La viuda de Nazareth), Marcela Mar (América Vicuña), Alicia Borrachero (Tía Escolástica) Héctor Elizondo (Don Leo), Ana Claudia Talancón (Olimpia Zuleta), Indhira Serrano (Barbara Lynch), Paola Turbay (mujer misteriosa), Noelle Schonwald (mujer misteriosa), Patricia Castañeda (dama).

Duración: 139 minutos.

Género: romántica.

Idioma original: inglés.

Productoras: Scott Steindorff. Woff Kroegen. Stone Village Pictures. New Line Cinema USA. 20th Century Fox International. Grosvenor Park Media.

Sinopsis: Adaptación de la famosa novela del Premio Nobel colombiano Gabriel García Márquez. Florentino Ariza es un poeta que se enamora locamente de Fermina Daza, una joven que pertenece a una familia acaudalada. Comienza entre ellos una apasionada correspondencia epistolar que se verá abruptamente interrumpida cuando el padre de ella, tras descubrir el idilio, decide llevársela lejos de su amante. (FILMAFFINITY).

Premios: Nominación al Globo de Oro a la mejor canción original ("Despedida").

Enlaces:

https://www.filmaffinity.com/es/film522524. html

https://www.imdb.com/title/tt0484740/

Tráiler en español

Tráiler en inglés

La película refleja la vida de finales del siglo XIX y principios del siglo XX en la costa Caribe de Colombia, cuando aparecen las penurias y varias guerras civiles azotan al país. Ocurre en un pequeño pueblo colombiano. 

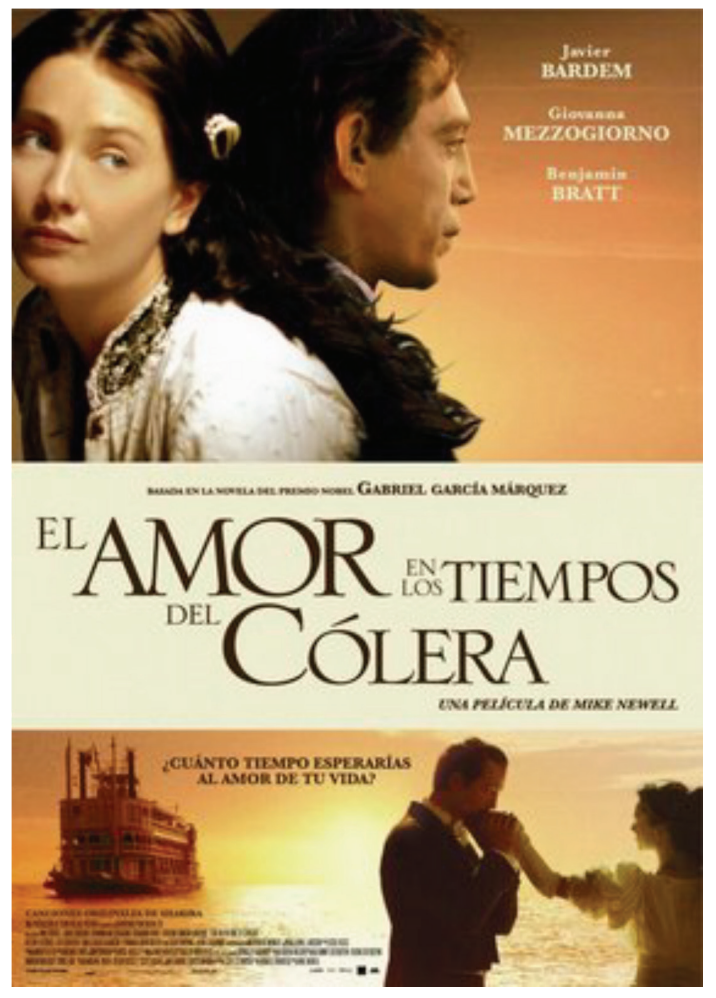

A las ciudades costeras llega la epidemia del cólera y los "síntomas del amor se confunden con los de esta enfermedad". Se hace una especie de analogía respecto al contagio del cólera como se puede contagiar el amor.

Florentino Ariza, el personaje interpretado por Javier Bardem (Unax Ugalde, en los años más jóvenes), está profundamente enamorado de Fermina Daza. Le propone matrimonio que ella acepta, pero el padre hace todo posible porque su hija de clase acomodada no se case con un empleado del telégrafo.

El cólera, como se sabe, es una enfermedad infecciosa aguda producida por Vibrio cholerae, que se caracteriza por diarrea abundante y vómitos ocasionales, por lo que inicialmente puede ser indistinguible de una diarrea del viajero o de otras patologías más benignas. De hecho, en la película cuando se hace el viaje en barco y se marean algunos pasajeros. La transmisión es sobre todo $12 \mathrm{~h}$ a 5 días tras la ingestión de alimentos o agua contaminados ${ }^{9}$.

También cuando el Dr. Juvenal va a casa de Fermina Daza a examinarla piensan que tiene cólera, hasta que el doctor diagnostica que tiene una infección intestinal y le pone tratamiento. Y todos se alegran de que no sea la temida enfermedad. Buscaron a este doctor porque era un experto en cólera al haber estudiado con un profesor en París.

En la película, al igual que en la novela ${ }^{10}$ también se aprecia claramente como la pandemia de cólera que sirve de contexto para contar la historia, no es el único "desastre" que sucede. Las pandemias pueden ir acompañadas de movimientos políticos y sociales, revueltas callejeras generalmente impulsadas por el miedo (el miedo al contagio, el miedo a no poder tener suministros básicos, el miedo a morir o a que las autoridades priven de bienes básicos...). En la calle hay bastantes referencias ("Es el cólera, hijo mí" minuto 13:02", asustada por lo que ve).

Asimismo, hay escenas en la película en las que se aprecia como la pandemia dificulta algunas cuestiones, como brindar ayuda a un barco en que algunos ocupantes estaban afectados por la enfermedad, cuerpos sin vida en el suelo, y había también personas vivas requiriendo ayuda...

Se muestran signos que ayudan a la protección de los que están vivos a evitar contagiarse, como la colocación de la bandera de la peste / cólera en el barco (50:50"), para indicar a otros que en el barco se ha decretado la epidemia. Esta señal de la bandera (cuatro cuadros alternando dos colores negro y amarillo), se usa al final de la película para que Florentino y Fermina, ancianos y tras el encuentro de su amor, puedan volver a su Cartagena por barco sin hacer ninguna parada intermedia, ni recoger mercancías.

A lo largo de la película se ve en diversos momentos las concepciones del amor y de la 
muerte, de diversas maneras. Se distingue el amor del sexo. Florentino, por ejemplo, tiene relaciones sexuales, pero sin amor. La primera relación sexual que tuvo fue una violación por parte de una mujer desconocida en un barco. Él lo consideró como una traición a la promesa hacia Fermina de permanecer virgen y puro hasta hacerlo con ella, pero luego separa amor de sexo, y llega incluso a hacer un listado de amantes y cómo fueron esas relaciones.

A Florentino, le sirve mucho escribir sobre sus sentimientos amorosos, sobre su relación casi platónica con Fermina, escribir cartas de amor a otras personas, incluso mezcla la correspondencia comercial y la afectiva. Esto es muy similar a las técnicas que trabajamos en duelo con los dolientes, tras la pérdida, cuando planteamos que escriban cartas (a la persona fallecida, a la muerte, a la enfermedad $u$ otras cuestiones...) o un diario de sentimientos del doliente hacia la persona perdida....

A continuación, se ha elaborado una tabla con las frases y eventos de la película relacionados con el amor y la muerte. En algunos casos hay mezcla de ambas cuestiones y se ha decidido encuadrar en la columna que se creía más conveniente (Tabla 2).

La película tiene también una analogía para hablar de esta doble vertiente de amor y muerte (dolor por pérdida). Y es la rosa (símbolo del amor) con espinas (asociada al dolor y el daño a sí mismo y a otros). Es la flor que aparece en los funerales, tras una pérdida de un personaje significativo. Cuando Fermina rechaza al doctor que la reexamina tras curarse de su dolencia, se refieren a ella como "rosa sin demasiadas espinas", Florentino, tiene ramos de rosas rojas, muy pequeñas en los momentos de pérdida, y desgaja una rosa roja con sumo cuidado para no pincharse.

En la película la música forma parte de la narrativa de la historia y la dota de significados diferentes y de ricos matices. Por ejemplo, la música de Shakira sobre el duelo llamada " $L a$ despedida" sobre el dolor de la pérdida. Repite varias veces "No hay más vida" porque se va la vida de las personas, no sólo de quien se va sino de quien se queda también. La canción es desgarradora y habla del dolor de la muerte de alguien a quien amas. Se escucha tras dos muertes muy seguidas, la de Olimpia Zuleta con la que Florentino tuvo una relación más próxima que con otras amantes; es una muerte de la que se siente culpable porque el marido descubre que su mujer había tenido un amante porque ve lo que él le había escrito en el abdomen "esto es mío" y una flecha en dirección al pubis. La otra muerte importante es la de su propia madre, que muere ya demenciada y tras una noche complicada para él. (Foto 2).

Florentino habla también de la muerte cuando hay sexo, como cuando la viuda de Nazareth, hablaba de su marido muerto mientras Florentino y ella tenían relaciones. Y después de esto es cuando él empieza a cambiar su manera de ver las cosas en la relación imposible con Fermina y dice "Empiezo a ser libre, el dolor se ha ido, ha desaparecido" (1h:02':10").

Con relación a todo lo anterior, está la idea de la oportunidad, de hacer las cosas cuando se pueden hacer y es posible. "Más vale llegar a tiempo que ser invitado" (Dr. Juvenal, 1h:40:50).

Por eso también Florentino se propone volver a declararle su amor a Fermina el mismo día del fallecimiento de su esposo el Doctor Juvenal. Él se encuentra con una de sus jóvenes amantes y oye "tocar a muerto" en las campanas de la catedral y piensa que debe de ser alguien importante. También para encontrar amor en el dolor, pero ella lo considera inicialmente como una ofensa grave y una falta de respeto a su marido. Aunque luego las cosas van cambiando y se produce el acercamiento entre ambos desde el amor. Ella tras el dolor de la muerte de su marido y él desde el dolor de no haberla podido tener hasta ese momento. 
Tabla 2. Referencias al amor y a la muerte en la película con frases de diversos personajes y canciones principales sobre ambos temas.

\begin{abstract}
REFERENCIAS AL AMOR EN LA PELÍCULA
Dile que sí, aunque te estés muriendo de miedo, aunque después te arrepientas, porque de todos modos te vas a arrepentir toda la vida si le contestas que no." "El amor en los tiempos del cólera" (le dice la tía a Fermina cuando Florentino le propone matrimonio) (14:20).

Florentino Ariza (FA): "No hay mayor gloria que morir por amor" (minuto 23:40).

Fermina Daza (FD) a su prima cuando están en las montañas: "Se puede ser feliz sin amor" (28:50).
\end{abstract}

FA a Don León en un funeral. "Esperaré a que su marido muera, esperaré lo que haga falta" (1h:03:30).

"Lo único que me duele de morir es no morir de amor" en ese momento Florentino supo que era idéntico a su padre. (le comenta Don León a Florentino respecto a su hermano, que era el padre de Florentino) (1h04:50).

FA: "Lo único que me interesa es el amor. Yo necesito amor, necesito el amor" (1h:08:50).

FA a Sara Noriega (maestra de educación cívica y una de sus amantes): ¿Qué es para ti el amor?

Sara Noriega: Todo lo que hacemos desnudos. El amor del alma de cintura para arriba y el amor del cuerpo de cintura para abajo.

FA: Amor dividido.

Doña Tránsito (madre de FA): "La única enfermedad que ha tenido es el cólera; confundes el cólera con el amor" (1h:21:30).

Dr. Juvenal a FD: "Lo más preciado en un matrimonio, no es la felicidad, es la estabilidad".

FD: Y el amor, nada es más difícil que el amor" (1h:29:30).

Declaración de intenciones de FA a FD (lo escribe a máquina): (1h48:00).

La edad no existe más que en el plano físico.

La esencia del ser humano resiste el paso del tiempo.

Nuestra vida interior es eterna. Lo que significa es que nuestro espíritu. Sigue tan joven y vigoroso, como cuando estábamos en la flor de la vida.

Hay que pensar en el amor como en un estado de gracia, No un medio para nada. Sino un origen y un fin, un fin en símismo...

\section{REFERENCIAS A LA MUERTE EN LA PELÍCULA}

Muerte de Dr. Juvenal, la familia recibe las condolencias, y le recuerdan diciendo: "Todavía padeceríamos el cólera de no haber sido por él" (minuto 3:40). El cortejo fúnebre va a la iglesia (5:40).

FA a FD en una nota: "Si no me mata el sufrimiento de tu corazón, puede hacerlo la ocupación, también está ese mal que surge, esta explosión de sangre, el abrazo asfixiante del cólera. Un mal más impredecible que la guerra, que se aferra a tu aliento, que no te suelta y que se aferra a tu vida y te suelta" (29:00).

FA: Así esperaba su regreso, esperar toda la eternidad, hasta la muerte si es necesario. Mi corazón es como el mar, infinito y sempiterno, aunque sea turbulento, como el embate de las olas" (31:00).

1h:25:20 Cementerio, funeral de Olimpia Zuleta. FA con rosas rojas con espinas en las manos. Mientras llueve: "El cielo llora por Olimpia y yo también, ¿qué he hecho? (culpa) (1h:26:55).

1h:28:00 Funeral cementerio por muerte de la madre, Florentino con rosas rojas.

1h:42:20 cuando FA ve a FD en una reunión social junto a su marido. "Veo joven a su esposo, y creo que ella puede morir antes que él, y yo también estoy mayor" (no cree que pueda alcanzar el amor de ella si el marido de ella no muere antes).

FA: No me da miedo la muerte pero si la vejez (1h 43:30).

1H 45:10 Funeral del Dr. Juvenal (continuación de lo visto al principio en 3:40 y 5:40). FA a FD: "Fermina llevo esperando 52 años, 9 meses y 4 días. La he amado desde la primera vez que posé sus ojos sobre usted".

FD: (enfadada): "Estás loco, eres una persona horrible, insensible. Estás en mi casa el día de la muerte de mi marido, habla de tus monstruos y de tus peores sentimientos. Lo que haces es pensar en ti... No quiero pensar en ti, sal de mi vida" (1h:45:10).

FD a FA: "Todo ha cambiado en el mundo".

FA: Yo no. ¿Y usted?

FD: Tengo 72 años y estoy...

FA: ...a punto de caer en la emboscada de la muerte. (1h:50:05).

Rev. Med. Cine. 2020; 16 (e), 293-310 Ediciones Universidad de Salamanca / @®® J. Med. Mov., 2020; 16 (e), $293-310$ [ 301 ] 


\section{REFERENCIAS AL AMOR EN LA PELÍCULA}

En la comida de FD con su familia cuando la hija le increpa por las visitas de FA tras el fallecimiento del padre, que le parecen "impropias". (1h:52:30).

Familiar a Ofelia (hija de FD): “¿No crees que el amor justifica todo lo que pueda pasar?".

Ofelia: "El amor es ridículo a nuestra edad, pero a la de ellos (la de su madre) es una cochinada".

FD: "Hace medio siglo se cargaron mi vida con ese pobre hombre porque éramos demasiado jóvenes y ahora nos lo quieren repetir porque somos demasiado viejos".

FA a FD: (1h:56:00) "Tal vez sea hora de preguntarnos por todos nuestros deseos de vivir. ¿qué hacemos con el amor que hemos dejado atrás desperdiciado?".

FD a FA: "Es increíble como algunos pueden ser felices durante demasiados años, en medio de muchos problemas y muchas vainas, ignorando si eso en realidad es amor o no". (se dan un beso).

FA: "Yo no he sido más feliz en toda mi vida".

FA a FD (en el barco van a mantener relaciones sexuales) 1h:59:25. "He esperado este momento 53 años. Me he conservado virgen para ti..."

FD: Mentiroso...

\section{MÚSICA SOBRE EL AMOR EN LA PELICULA}

https://www.youtube.com/watch?v=5h102eY7K5Y ("Hay amores", duración 3:27") "Hay amores que se vuelven resistentes a los daños". Como el vino que mejora con los años. Así crece lo que siento yo por ti" // Hay amores que se esperan al invierno y florecen. Y en las noches del otoño reverdecen. Tal como el amor que siento yo por ti".

\section{REFERENCIAS A LA MUERTE EN LA PELÍCULA}

- ¿Y hasta cuándo cree usted que podemos seguir en este ir y venir del carajo? - le preguntó. Florentino Ariza tenía la respuesta preparada desde hacía cincuenta y tres años, siete meses y once días con sus noches. - TODA LA VIDA - dijo." (2h:02:00).

FA: (2h:02:50) "Tras 53 años, 7 meses y 11 días con sus noches, mi corazón se sintió realizado, y descubrí que es la vida y no en la muerte, la que carece de límites" (fin de la película y canción... "Cada día pienso en ti, cada día pienso más en ti...sigo pensando en ti...".

\section{MÚSICA SOBRE LA MUERTE/DUELO}

https://www.youtube.com/watch?v=hu6yFOeZVDY ("La despedida", duración 2:50")

No hay más..., vida, Iluvia, risa, brisa, llanto, miedo, canto (primera estrofa). No hay más... sueño tiempo, miedo, fuego, vida, rabia, sueño,... Llévame donde estés, cuando alguien se va ¿qué se queda? / Cuando alguien se va, el que se queda sufre más...
El tiempo es algo importante para el amor y para el duelo; en la película Florentino lleva la cuenta del tiempo que esperaba el amor de Fermina, el deseo de consumar su amor a nivel físico, su conclusión de que la vida no tiene límites... Y Florentino también lleva la cuenta de sus amantes, de su sexo sin amor, hasta que encuentra el amor y el sexo al mismo tiempo. Y ahí encuentra para él la felicidad (Foto 3).

\section{FRASES AMOR Y DOLOR, COMO LAS DOS CARAS} DE UNA MISMA REALIDAD ANTE LAS DIFICULTADES (EXTRAíDAS DE LA NOVELA ${ }^{10}$, PERO NO PRESENTES EN LA PELí́CULA).

"Los seres humanos no nacen para siempre el día en que sus madres los alumbran, sino que la vida los obliga otra vez y muchas veces a parirse a si mismos" (Gabriel García Márquez; El amor en tiempos de Cólera). Habla del ciclo de la vida, 


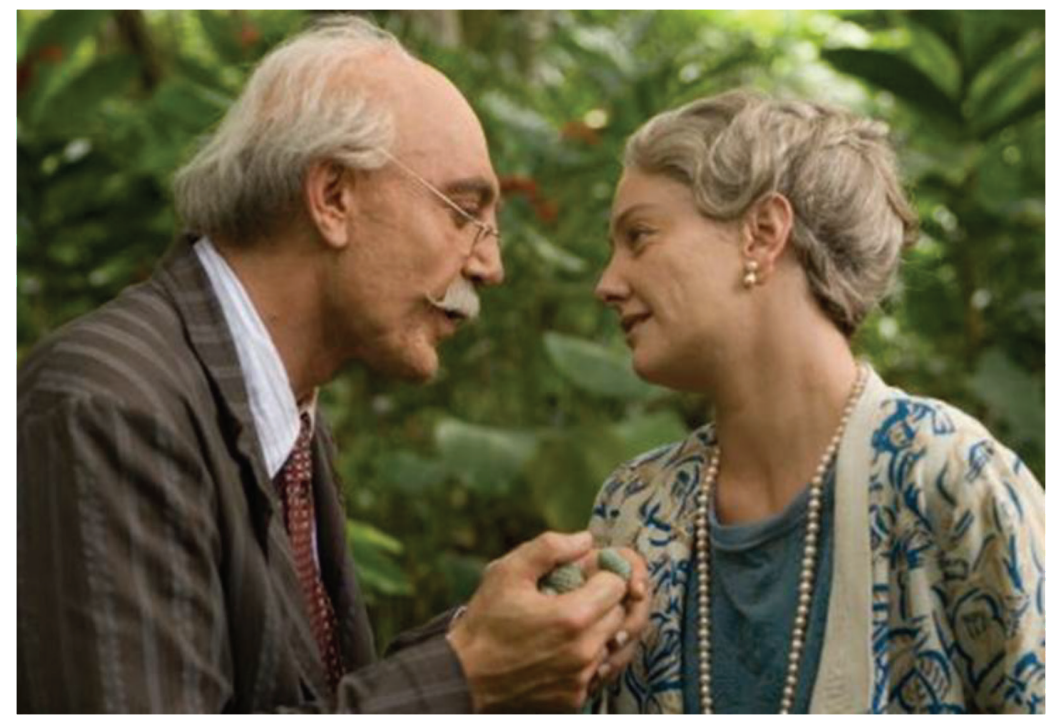

Foto 2. Florentino Ariza y Fermina Daza, en el reencuentro tras las experiencias de amor y muerte que han tenido cada uno de ellos.

la capacidad de afrontamiento, la resiliencia ante la adversidad.

"Era todavía demasiado joven para saber que la memoria del corazón, elimina los malos recuerdos y magnifica los buenos, y que gracias a ese artificio, logramos sobrellevar el pasado" Nos remite al afrontamiento del duelo, implicación activa en el propio afrontamiento para conseguir

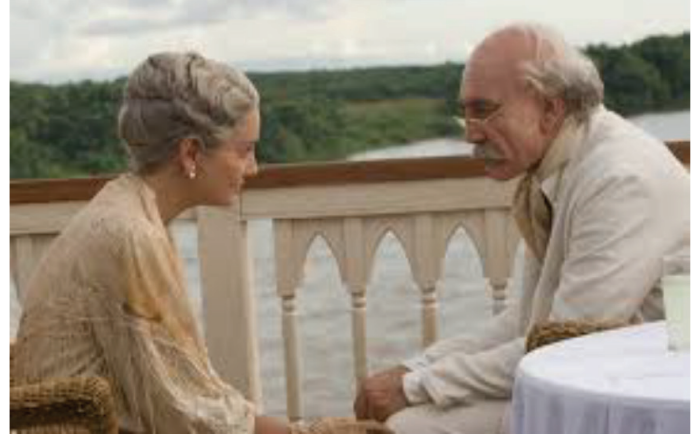

Foto 3. Fermina Daza y Florentino Ariza en el barco juntos en su amor. resultados y bienestar psicológico, calidad de vida.

"Otra cosa bien distinta habría sido la vida para ambos, de haber sabido a tiempo que era más fácil sortear las grandes catástrofes matrimoniales que las miserias minúsculas de cada día. Pero si algo habían aprendido juntos era que la sabiduría nos llega cuando ya no sirve para nada". (El amor en los tiempos del cólera).

La película es un Canto a la vida, al poder del amor, a la vejez, a la perseverancia, la esperanza, la confianza en el cambio, el poder de la espera, saber disfrutar de la vida hasta el final.

"El amor es el anhelo de abrazar a una persona con fuerza y estar en el mismo lugar que ella. El deseo de abrazarla dejando fuera al mundo entero. La nostalgia del alma de encontrar un refugio seguro" (Orhan Pamuk escritor turco, Premio Nobel de Literatura en 2006). 
La CiUdad de la Alegría: entre el eStigma, LA POBREZA Y LOS PREJUICIOS.

El verdadero heroísmo está en la calidad de la lucha (La Ciudad de la Alegría)

Título: La Ciudad de la Alegría.

Titulo original: City of Joy.

País: EE. UU. Reino Unido. Francia.

Año: 1992.

Director: Roland Joffé.

Música: Ennio Morricone

Fotografía: Peter Biziu.

Montaje: Jerry Hambling.

Guión: Mark Medoff basado en el libro homónimo de Dominique Lapierre.

Intérpretes: Patrick Swayze (Dr. Max Lowe), Pauline Collins (Joan Bethel), Om Puri (Hazari Pal), Daniel Colle, Shabana Azmi (Kamla H Pal), Ayesba Darker (Amrita, H Pal), Santu Chowdhury (Shambu H Pal), Imran Badsah Khan (Manooj H Pal); Art Malik (Ashok Ghatak), Nabil Shaban (Anouar), Debatosh Ghosh (Ran Chandler), Suneeta Sengupta (Poomina), Mansi Upadhya (Meeta), Shyamanand Jalan (Ghatak Padrino), Shyamalal Sengupta (Gangooly, hombre loco), Rudraprasad Sengupta (Chomotkar), Baroon Chakaborty (Said), Masood Aktar (Rassoul), Loveleen Mishra (Shanta), Pavan Malhotra (Ashish), Dipti Dave (colegiala).

Duración: 130 minutos.

Género: drama, drama político- social.

Idioma original: inglés.

Productoras: Allied Filmmakers. TriStars Pictures. Light Motive.

Sinopsis: "Drama basado en el best-seller homónimo de Dominique Lapierre, sobre las miserables condiciones en que viven los desheredados en la India. Un cirujano norteamericano (Patrick Swayze), tras perder a un paciente, se desmorona y decide viajar a la India en busca de paz espiritual. En Calcuta, tras ser golpeado y robado, es ayudado por un granjero (Om Puri) que lo lleva a una clínica en la "Ciudad de la alegría", una de las zonas más pobres de la ciudad (FILMAFFINITY)".

\section{Enlaces:}

https://www.filmaffinity.com/es/film956392.

html

https://www.imdb.com/title/tt0103976/

Tráiler en español

Tráiler en inglés

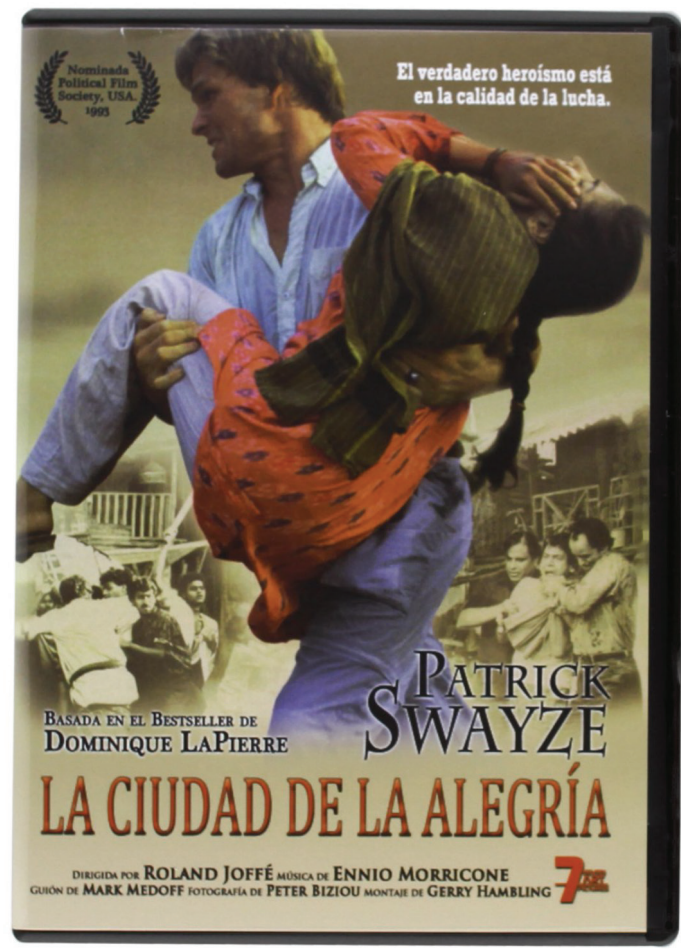

\section{ALEGRÍA EN OTRA PARTE INESPERADA DEL MUNDO}

Esta obra cinematográfica está basada en una obra literaria del mismo nombre del escritor francés Dominique Lapierre ${ }^{11}$, que fue un auténtico bestseller cuando se publicó.

El punto de partida de la película es de un médico atormentado por la culpa de no haber podido salvar a una joven paciente y por la educación de su estricto padre. Lo cual le conduce 
a una situación de pérdida de confianza, culpa, crisis personal vital de la que no sabe cómo salir, ni qué rumbo tomar... Que ha perdido lo que pensaba que había construido en su vida en Norteamérica, por lo que ha luchado, y de repente se cuestiona todo, incluido a sí mismo.

Una de sus pacientes pediátricas más queridas, fallece delante de él en la mesa de operaciones; entra en parada cardiorrespiratoria, se inician maniobras de reanimación pero permanece en asistolia y se ve cómo alguien corta el tubo orotraqueal (como analogía de la vida que se ha cortado en la juventud y que el médico lo percibe también como que se trunca su carrera profesional y su persona por completo).

Cuando llega allí le roban lo que tiene, debe ser atendido en un dispensario de la Ciudad de la Alegría, le retienen el pasaporte hasta que abone lo que debe, en el hotel... por lo que su vida da un giro de 180 grados en cuestión de horas.

En la película las pérdidas son evidentes en todos los personajes, son de todo tipo, algunas pérdidas más visibles- objetivas y otras pérdidas más intangibles, simbólicas.

La lepra que se extiende rápidamente entre la población de Calcuta y produce muchas reacciones de miedo al contagio a acercarse a alguien enfermo, indefensión si hay un contagio accidental o por cuidar de alguien enfermo. Se considera que las personas que contraen la lepra pueden merecerse esta enfermedad que provoca mucho distanciamiento social.

La lepra o enfermedad de Hansen es una enfermedad infecciosa crónica causada por el Mycobacterium leprae. Afecta la piel, la mucosa de las vías respiratorias altas, los ojos y los nervios periféricos. El período de incubación de la enfermedad es, en promedio, de cinco años. Los síntomas pueden tardar hasta veinte años ${ }^{12}$. Sus complicaciones más severas son la desfiguración, la deformidad y la discapacidad (ya sea por el compromiso neurológico o la ceguera). El contagio se produce entre una persona enferma susceptible de transmitir la enfermedad (no todas pueden transmitirlo; la medicación elimina esta posibilidad) y una persona sana susceptible (algunas personas eliminan el bacilo). Es decir, conjugar durante un tiempo, un enfermo que actúe como agente infeccioso y sano con predisposición especial, para que se produzca el contagio.

Hay personajes en la película que se alejan de las concepciones de contagio de la lepra y de la idea de que hay que apartarse de las personas que padecen la enfermedad. Por ejemplo, la mujer de Hasari, que dice "Si tienes el corazón limpio, no pasa nada". Lo que se relaciona con aspectos morales, religiosos y espirituales complejos. Incluso hay alusiones a "La lepra no es contagiosa, mi hija no".

Incluso personas con lepra tienen otras grandes cualidades. Por ejemplo, el personaje del incapacitado que está en su cajón por pérdida de extremidades inferiores consecuencia de la lepra dice: "Puede que no tenga el cuerpo de una garza pero tengo la vista de un águila". Por lo que es perfectamente consciente de sus habilidades y de cómo puede potenciarlas para que sean útiles y usarlas para compensar sus dificultades.

Hay otras referencias a la lepra en varios momentos de la película, y se aprecian los momentos de normalidad de la enfermedad (y como es integrada por personas locales) y el estigma que produce en otras personas saberse cerca de leprosos, como un riesgo añadido de alto contagio percibido para ellos. Las personas con lepra forman parte de la Ciudad de la Alegría, donde se acepta lo diferente y las capacidades de cada uno. Y ellos tienen un papel importante en la lucha que hacen con las mafias los integrantes de la Ciudad de la Alegría para recuperar su lugar y su independencia. En este lugar los leprosos son objeto de ataque, casi como algo a exterminar, porque se les ha desprovisto de su dignidad como personas. 
Hay una frase especialmente contundente (1h23:30) en boca de uno de los leprosos: "Este mal que padecemos no es un castigo por los pecados del pasado, sino una enfermedad"

La película nos muestra los grandes cambios que hay entre las culturas, tanto económica como socialmente y la forma de actuar, y como podemos aprender también de otras formas de vivir, de otras culturas, de personas que viven con lo imprescindible y a pesar de todo son felices y comparten lo que tienen.

Se ven las mafias que acaparan el negocio de los rackshaw, que suponen el sustento de muchas familias, que no tienen otro medio de vida, y que tienen que trabajar mucho a costa de su salud para conseguir dinero suficiente para quien "le permite trabajar en una zona determinada" y para dar de comer a su familia, que es lo que le pasa a Hasari.

\section{BUSCAR EL CAMINO ENTRE LAS PÉRDIDAS PROPIAS Y DE OTROS}

En el personaje de Max se ve el conflicto interno, el malestar evidente en que se encuentra por tener la sensación de ser una persona no válida, ni para sí mismo ni para otros, por eso hay conversaciones muy contundentes con Joan en que las confrontaciones por ambos lados están a la orden del día. Ella intenta ayudarle con preguntas, pero él no sabe responderse ni encontrar a qué agarrarse en su vida desesperanzada...

Hay conversaciones entre ellos francamente muy interesantes...

Max: No intente reclutarme ¿ No hay católicos no practicantes?, Pues yo soy médico no practicante. (...)

Joan ¿Por qué no ejerce?

Max: Porque no me gusta la gente enferma.

Max a Joan: ¿Es usted una excéntrica o ha venido a hacer Penitencia por algún pecado de juventud?
Si pretende curarse debe dejar de maltratarse. (Hermana Joan a Max).

No soy de las que aman a una sola persona. Me siento mejor si lo comparto con los demás. (Joan a Max).

Es tan estúpido como pedir que te echen una mano y te rechacen. (Joan a Max).

En la vida tenemos 3 opciones, huir, ser espectador o comprometerse. (Joan a Max).

Esta última frase es toda una filosofía de vida, una declaración de intenciones y una manera de que Max se plantee qué desea hacer; pero esto también lo podemos hacer extensivo a cada uno de nosotros y plantearnos qué actitud tomamos ante la vida y si deseamos seguir en la misma línea.

Max va recuperando la confianza en sí mismo, en sus cualidades como persona válida, y en sus habilidades médicas (salva a la mujer gestante que tiene un parto complejo y se siente feliz por haber solucionado el problema obstétrico).

Cuando él se va empoderando por dentro, encontrando su camino, se convierte en sostén de otros. La imagen más paradigmática es la del cartel de la película cuando coge en brazos inmediatamente a la chica que ha recibido cortes en la cara por parte de las mafias. La lleva en brazos y la sutura las heridas, le da recomendaciones y con sumo cariño la acompaña en el proceso de curación de las mismas; Max la ayuda con sus conocimientos, de la misma manera que Joan o Hasari y su familia le ayudan a él con su ejemplo de vida. Y empieza a recuperar las ganas de vivir renovados, resurgiendo de sus cenizas cual ave Fénix.

Hacia el final de la película (2h:01:00) se produce también una conversación importante. Ocurre tras la boda de la hija de Hasari, que ha supuesto un gran esfuerzo porque desde el principio no tenía dinero para la dote y al final 
lo consigue, con mucho esfuerzo, a pesar de la afección pulmonar provocada por la tuberculosis que padece [se produce un sangrado en la propia boda (se empapan los vendajes toraco-abdominales) y Hasari no quiere que nadie salvo Max le ayude, porque el médico se da cuenta].

Max: Nunca me he sentido tan vivo.

Joan: Eres libre para irte.

Max: Soy libre para quedarme.

\section{PERDIDAS Y ALEGRÍAS. CURAR Y SANAR}

Ante las situaciones de pérdidas se puede apoyar la persona en el amor, dentro de sí mismo (todos somos fuentes de amor si sabemos buscar en nuestro interior, pero también el amor se agota dentro), y en el amor que otros nos dan (que también tienen sus surtidores de amor, cariño, alegría...). El poder del amor es un punto de apoyo en los momentos difíciles, en los que sentimos que perdemos el rumbo, que estamos desorientados porque la vida nos ha dado un buen varapalo y no entendemos lo que nos ha sucedido.

Esto nos lleva al desarrollo de la resiliencia, a ver las crisis como oportunidades de crecer (ya lo dicen los dos pictogramas en chino que nombran la crisis, problema y oportunidad). A ver la oportunidad de crecer, cuando algo nos pone a prueba, a ver dentro de nosotros mismos cualidades ocultas y reorientar nuestro camino. Esto es lo que hace Max en la película, con varios momentos que le hacen aterrizar en la realidad, en su presente y en su "Aquí y ahora", y reorientar su rumbo sin lamerse infinitamente sus heridas, mirando hacia delante y decidiendo lo que quiere hacer por sí mismo y por otros...

Todo esto, y la película nos lo demuestra, está por encima, o va más allá de las propias creencias y concepciones espirituales, porque desde cualquier visión religiosa o más bien espiritual se puede encontrar el modo de ser la persona que uno desea ser, a pesar de lo que nos haya sucedido.

La lepra se ha considerado durante mucho tiempo una enfermedad del alma, más que del cuerpo, como una especie de juicio divino en que el veredicto estaba a la vista, y la sanción, penitencia o culpa la llevaba la persona. Y esto ha hecho mucho daño y ha supuesto mucho sufrimiento para personas afectadas.

Por eso en la película lo que se propugna es mirar a las personas con los "ojos del corazón" y que las personas merecemos la pena por nuestro interior, no por las marcas externas de una enfermedad que es estigmatizante. Así podemos luchar por mejorar las cosas en nuestro entorno, no quejarnos y construir las bases del mundo en que queremos vivir. Es paradójico y también revelador que en un lugar como la India donde la pobreza es extrema, las personas encuentren la alegría de vivir (Foto 4).

Hay que diferenciar curar de sanar. Cuando hablamos de "curar" nos referimos a que la situación de enfermedad / malestar remita, o regrese a los niveles basales iniciales. Las enfermedades se curan cuando ya no es necesario tratar la enfermedad (aunque puede que haga falta tratar las secuelas). La curación es algo más objetivo (un resultado, muchas veces), más unidireccional, más pasivo, menos proactivo (hay menos búsqueda en la persona).

Cuando hablamos de "sanar", se hace referencia a reparar el daño, restituir el bienestar... Puede que no haya curación, pero no hay malestar; puede que haya que seguir tratando la enfermedad y/o las secuelas, pero hay una aceptación de la situación, una adaptación a la realidad, una seguridad en la persona en sí misma, una energía que mana y que empapa todo. La sanación tiene un componente subjetivo, personal, biográfico y que implica interacción consigo mismo y con los demás (bidireccional), hay una comunicación fluida, positiva. Es un proceso más activo. 
Nos curamos de las heridas físicas, nos sanamos de las heridas emocionales. $Y$ a veces quedan cicatrices más o menos visibles, pero que forman parte de nosotros y las integramos en nuestra propia identidad.

A veces es importante encontrar belleza en el caos, felicidad en lo enrevesado y caótico... Hasari lo plantea de este manera: " $¿ N o$ te llena de alegría ver toda esta catástrofe?" (tras ganar la batalla a la mafia, pero ver todos los destrozos que se han originado), y haciendo honor al refrán de que "la unión hace la fuerza" (todos los subyugados se unen contra el enemigo común para vencerlo). Aprovechan una situación de pérdida (el fallecimiento del "padre mafioso" que era algo más magnánimo que el hijo, que ya saben de sus intenciones y no desean que siga acaparando poder y usando sus métodos, por eso le ponen coto lo antes posible) (Foto 5 ).

La película acaba con una frase basada en la generosidad y gratitud de los seres humanos, y en la comunicación cósmica de energía de ayuda altruista. "Todo lo que no se da se pierde" (Hasal PAL- Hasari).

\section{CONCLUSIONES}

- A la vista de las películas visionadas y de los aprendizajes que nos pueden aportar, se pueden extraer las siguientes conclusiones:

- El amor, el cariño, la comunicación afectiva son las necesidades que todos tenemos ante situaciones de pérdida. En muchos casos se convierte en la mejor medicina que tiene un efecto "sanador".

- Es importante saber disfrutar de la vida, de los momentos buenos, de las personas que nos aprecian y nos dan amor. Para que cuando llegue el momento de la perdida nos podamos refugiar en ese amor, que nos haga más llevadero los momentos difíciles.

- Sentirse útil y sentirse importante para una persona, nos da energía vital para las

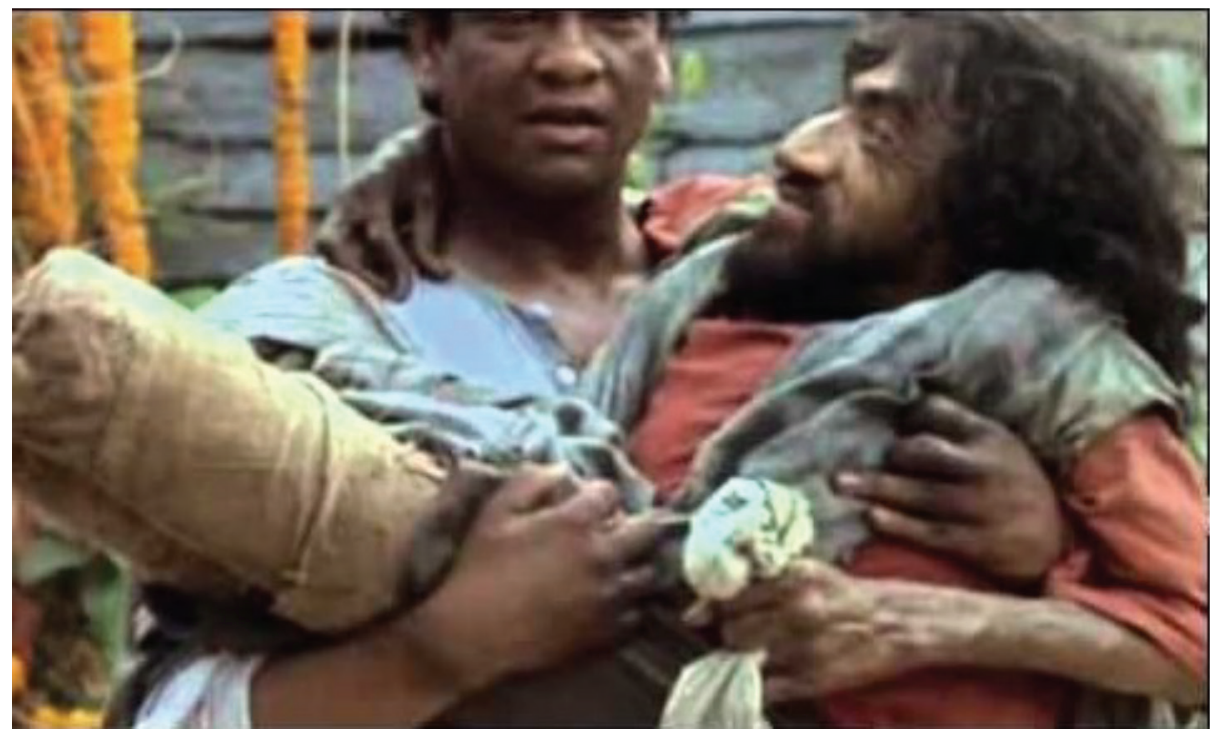

Foto 4: Ayuda mutua, un personaje coge en brazos a otro con secuelas por la lepra en extremidades inferiores y superiores. 


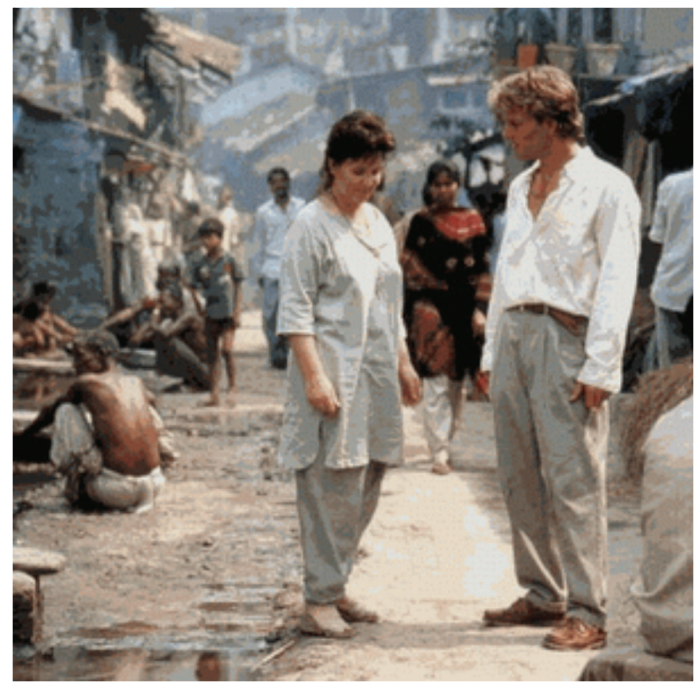

Foto 5: Joan y Max en la Ciudad de la Alegría.

dificultades añadidas que van surgiendo en la vida de manera inesperada.

- Cuando hay una situación de pandemia y se toman medidas de confinamiento y otras medidas de protección, es necesario respetarlas y prestar atención a las personas y objetos que nos aportan energía afectiva para tolerar las dificultades.

- En las tres películas se ve claramente que la muerte y las pérdidas en general van unidas a conflictos y revueltas sociales. Esto también se puede ver en la reciente El jardín secreto (2020, Reino Unido-Francia, Director Marc Munden), en que hay muerte de los padres de la niña protagonista por cólera y se producen revueltas callejeras asociadas también a la separación de India de Pakistán.

- Los conflictos ante una pérdida pueden ser externos (sociales, callejeros) pero también internos (personales, biográficos, morales, espirituales...).
- Encontrar la paz interior es un camino personal que incluye la sanación de las propias heridas; todos somos "sanadores heridos".

"Todo concluye. Hay cosas que mueren de golpe, sin volver la cabeza, como es el caso de un pequeño gorrión contra el parabrisas. Otras, van yéndose despacio y son tan irrecuperables como aquéllas, así la ternura o el conocimiento, o la dulzura de unas piernas, o en definitiva el amor. Es una pena, pero todo concluye como se quedan interrumpidos en las fotografías los amores eternos con dedicatoria, las banderas, el organdí de fiesta movido por el viento, los atentados, la cara eterna de los niños, ese tiempo de escuela detrás de una mesa, esférico y azul como el globo terráqueo, los mejores reportajes de guerra, o en definitiva las vidas más corrientes"13.

\section{REFERENCIAS}

1. Pérez-Salés P. Trauma, culpa y duelo. Hacia una psicoterapia integradora. Bilbao: Desclée de Brouwer; 2006.

2. Worden JW. El tratamiento del duelo. Asesoramiento y terapia. Barcelona: Paidós; 1997.

3. Neimeyer RA. Aprender de la pérdida: Una guía para afrontar el duelo. Barcelona: Paidós; 2009.

4. Payás A. Las tareas del duelo. Psicoterapia del duelo desde el modelo integrativo relacional. Barcelona: Paidós; 2011.

5. Bermejo JC. La muerte enseña a vivir. Vivir sanamente el duelo. Madrid: San Pablo; 2003.

6. Bottasso O. Amar la vida / Wit (2001); un caso donde el arte de cuidar aparece desdibujado. Rev Med Cine [Internet] 2020;16(1): 17-23.

7. González Pozega C. Cólera: lucha contra la epidemia en un entorno hostil. Rev Med Cine [Internet] 2015; 11 (2) 82-6. 
PÉRDIDAS, MUERTE Y DUELO ANTE PANDEMIAS: “PONER AMOR DONDE HAY DOLOR”. EL VELO PINTADO, EL AMOR EN TIEMPOS DE CÓLERA Y LA CIUDAD DE LA ALEGRÍA M. ${ }^{a}$ PATRICIA ACINAS ACINAS

8. Maugham WS. El velo pintado. Barcelona: Editorial Bruguera; 2007.

9. OMS. Cólera. Centro de Prensa. Notas descriptivas. [internet] 17 de enero de 2019 [Consultado el 29 de agosto de 2020].

10. García Márquez G. Amor en tiempos de cólera. Barcelona: Penguin Random House; 1985.
11. Lapierre D. La ciudad de la alegría. Barcelona: Planeta; 2010.

12. Muñoz Molina L, Constanza Corrales L, Hernández Barbosa R, Navarrete J. La lepra. Patología con conciencia histórica. Enf Inf Microbiol 2012; 33 (1): 32-43.

13. Rubio Montaner P. En: Saval L, García Gallego J (eds). Litoral femenino: Literatura escrita por mujeres en la España Contemporánea. Málaga: Litoral Femenino; 1986.

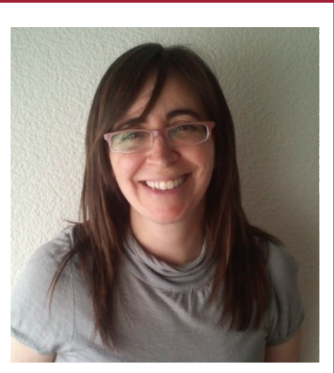

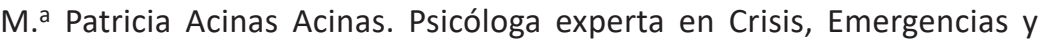
Catástrofes. Miembro Co-Fundadora y Secretaria de SEPADEM (Sociedad Española de Psicología Aplicada a Desastres, Urgencias y Emergencias). Lleva trabajando más de veinte años en el ámbito extrahospitalario y hospitalario en Servicios Médicos (incluyendo Cuidados Paliativos). Compagina actividad asistencial y docente en másters y cursos en varias universidades. Sus áreas de interés son: intervención en crisis, trauma, duelo (por diversas pérdidas), (auto)cuidado de profesionales sanitarios y comunicación en entornos sanitarios. Diversas publicaciones relacionadas con estos temas. 